\title{
CARDIAC OUTPUT IN NORMAL MEN DURING STEADY-STATE EXERCISE UTILIZING DYE-DILUTION TECHNIQUE*
}

\author{
BY \\ ARTHUR M. LEVY, BURTON S. TABAKIN, AND JOHN S. HANSON \\ From the Cardiopulmonary Laboratory of the University of Vermont College of Medicine, \\ Mary Fletcher Hospital, Burlington, Vermont, U.S.A. \\ Received February 2, 1960
}

Measurement of cardiac output by various methods in both health and disease has received considerable attention lately. Because of the understandable hesitancy of investigators to subject normal subjects to prolonged, vigorous exercise in the upright position during cardiac catheterization, few observations of man's cardiac output in his normal exercising position have been made (Chapman and Fraser, 1954; Mitchell et al., 1958; Sproule et al., 1960). Circumvention of the dangers inherent in determination of output by the Fick principle by means of a safe and relatively simple technique would allow valuable study of this important problem.

The advent of accurate and simple indicator dilution technique has provided investigators with a possible solution to this problem. This report presents the results of 64 determinations of cardiac output by the dye-dilution method in 12 normal men during 20 -minute periods of steady-state treadmill exercise. Twenty-three additional determinations were made in 11 of them during a subsequent 20-minute exercise period. The reliability of the method in resting and exercising subjects is discussed. Additional application of the technique will be presented in a subsequent communication (Levy et al., 1961).

\section{Materials AND Methods}

Subjects and their Preparation. Twelve male university undergraduate and medical students ranging in age from 20-26 years were studied. Anthropometric data for these subjects appear in Table I. Several days before the actual cardiac output determinations, each subject was required to perform two 20-minute, steady-state walks on the motor-driven treadmill at a speed of 3 miles an hour on a 4-degree grade. The following procedure was invariably followed for the output study itself: prior to the performance of exercise, a \#17 Rochester needle was inserted into a median cubital vein and connected by a 3-way Luer-lock stop-cock to a saline infusion. Following this a Riley arterial needle was inserted into the brachial artery of the opposite arm, and the needle threaded for its full length up the artery. This arm was strapped to an armboard, taking great care not to compress any vascular channels.

Instrumentation. Cardio-green dye $\dagger$ was used for all indicator dilution curves. Injection of the dye via the 3-way stopcock into the indwelling Rochester needle in the cubital vein was effected from previously-calibrated glass chambers $\ddagger$ varying from 1.53 to $1.58 \mathrm{ml}$. content including the volume of a one-way stopcock which was connected to a $10 \mathrm{ml}$. Luer-lock syringe. This syringe was filled

\footnotetext{
* This investigation was carried out during the tenures of a Post-doctoral Research Fellowship of the National Heart Institute (Dr. Levy), and a Daland Medical Research Fellowship of the American Philosophical Society (Dr. Hanson). Work was supported by Training Grant HTS 5286 and Research Grant H-4010(C1) of the National Heart Institute, Bethesda, Maryland.

$\dagger$ Manufactured by Hynson, Westcott and Dunning, Baltimore,, Md.

₹ Manufactured for this purpose by Becton-Dickinson Co, Rutherford, N. J. 
TABLE I

ANTHRopometric Data

\begin{tabular}{|c|c|c|c|c|c|}
\hline Subject & Age & Sex & $\begin{array}{l}\text { Height } \\
\text { in. }\end{array}$ & $\begin{array}{l}\text { Weight } \\
\text { lb. }\end{array}$ & $\begin{array}{c}\text { Surface area } \\
\mathrm{m} .^{2}\end{array}$ \\
\hline 1. J.G. & 23 & $\mathbf{M}$ & $68 \cdot 5$ & 170 & $1 \cdot 92$ \\
\hline 2. D.B. & 24 & $\mathbf{M}$ & $71 \cdot 3$ & 143 & $1 \cdot 84$ \\
\hline 3. P.R. & 24 & $\mathbf{M}$ & $69 \cdot 0$ & 158 & $1 \cdot 87$ \\
\hline 4. G.Y. & 22 & $\mathbf{M}$ & $72 \cdot 3$ & 182 & $2 \cdot 05$ \\
\hline 5. P.W. & 26 & $\mathbf{M}$ & $71 \cdot 0$ & 170 & $1 \cdot 96$ \\
\hline 6. F.Z. & 26 & $\mathbf{M}$ & $68 \cdot 3$ & 170 & 1.92 \\
\hline 7. M.B. & 25 & $\mathbf{M}$ & $71 \cdot 3$ & 181 & $2 \cdot 02$ \\
\hline 8. T.L. & 24 & $\mathbf{M}$ & $71 \cdot 0$ & 177 & $2 \cdot 00$ \\
\hline 9. T.H. & 22 & $\mathbf{M}$ & $67 \cdot 3$ & 187 & 1.98 \\
\hline 10. A.B. & 23 & $\mathbf{M}$ & $67 \cdot 3$ & 152 & $1 \cdot 82$ \\
\hline 11. D.A. & 25 & $\mathbf{M}$ & $71 \cdot 8$ & 179 & $2 \cdot 03$ \\
\hline 12. R.G. & 20 & $\mathrm{M}$ & $72 \cdot 3$ & 166 & $1 \cdot 97$ \\
\hline
\end{tabular}

with sterile saline to effect rapid and complete injection of the dye. During intervals between dye injections the venous needle was kept open with a continuous saline drip.

Dye curves were recorded using the Waters XC-50B cuvette, the output of this cuvette being amplified in the oximeter-dye curve amplifier of the Electronics for Medicine DR-8 photographic research recorder. Paper speed of $5 \mathrm{~mm}$./sec. was used with superimposed 1-sec. time lines for all curves. An example of the curves obtained during a 20 -minute walk in one subject is shown in Fig. 1.

The Waters cuvette was attached to the indwelling arterial needle by means of a glass adapter tip and plastic connecting tube. Arterial samples were withdrawn through the cuvette at rates of $30-40 \mathrm{ml}$./min., a speed sufficient to obliterate all arterial pulsation on the oximeter baseline. The entire system was cleared with heparinized saline after inscription of each dye curve, and great care was taken to insure patency of the arterial needle and cleanliness of its hub.

Fifty ml. of arterial blood were withdrawn from each subject. Various dilutions of dye were made with aliquot blood samples, and duplicate calibration curves made with the cuvette for each subject. A zero line and a minimum of two concentration values were plotted for each determination. Cardiac output was calculated by the method of Hamilton et al. (1932). Mean values and standard deviations were established for the cardiac outputs.

Procedure. Dye injection and arterial sampling were performed in each subject as close as technically possible to the $3 \mathrm{rd}, 5 \mathrm{th}, 7 \mathrm{th}, 9 \mathrm{th}, 12 \mathrm{th}, 15 \mathrm{th}$, and 20 th minutes of the steady-state walk which was performed at a speed of 3 miles an hour on a 4-degree grade. Occasional outputs were recorded during the first two minutes of some walks. Following a 20-30 minute rest, 10 subjects repeated their walk, and cardiac output was determined at the 10th and 12th minutes.

All subjects breathed through a Rudolph high-velocity valve attached to a previously-described (Tabakin and Hanson, 1960) collecting system of 150-litre Douglas bags. Although expired air collections were not made during the output determinations, they were performed through this same system on a subsequent identical treadmill walk to determine the constancy of ventilatory steadystate for each subject. 

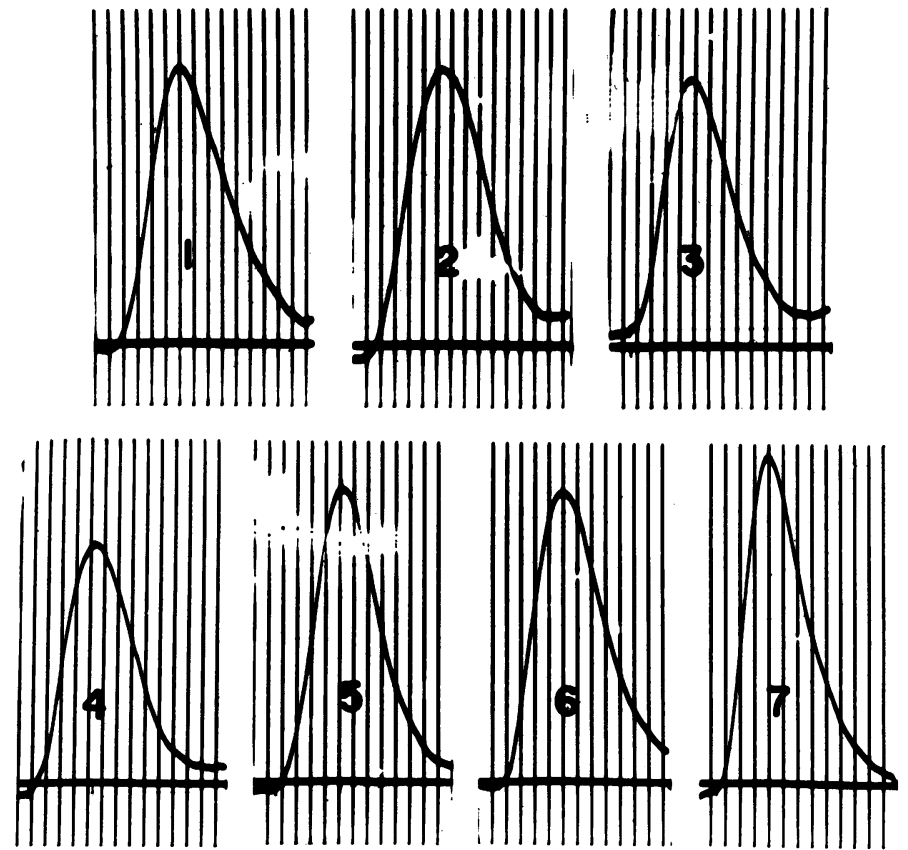

Fig. 1.-Series of 7 consecutive indicator-dilution curves in Subject 4 (G.Y.) during 20-minute treadmill walk.

TABLE II

Cardiac Output in Litres a Minute During 20-Minute Exercise Periods

\begin{tabular}{l|c|c|c|c|c|c|c|c|c|c}
\hline $\begin{array}{l}\text { Subject } \\
\text { No. }\end{array}$ & \multicolumn{7}{|c|}{ Time-minutes } \\
\cline { 2 - 7 } & $1-2$ & $3-4$ & $5-6$ & $7-8$ & $9-10$ & $12-13$ & $15-16$ & $19-20$ & Mean & S.D. \\
\hline 1. J.G. & - & $11 \cdot 0$ & $11 \cdot 9$ & - & $13 \cdot 2$ & $11 \cdot 8$ & $13 \cdot 9$ & $13 \cdot 7$ & $12 \cdot 6$ & $1 \cdot 2$ \\
\hline 2. D.B. & - & - & - & $11 \cdot 9$ & $11 \cdot 1$ & $11 \cdot 5$ & - & $11 \cdot 3$ & $11 \cdot 5$ & $0 \cdot 4$ \\
\hline 3. P.R. & $14 \cdot 0$ & - & $15 \cdot 0$ & - & $13 \cdot 9$ & - & - & - & $14 \cdot 3$ & $0 \cdot 6$ \\
\hline 4. G.Y. & - & $14 \cdot 9$ & $14 \cdot 7$ & $20 \cdot 4$ & $20 \cdot 0$ & $18 \cdot 3$ & $15 \cdot 8$ & $16 \cdot 6$ & $17 \cdot 2$ & $2 \cdot 4$ \\
\hline 5. P.W. & - & - & - & $15 \cdot 7$ & $14 \cdot 4$ & $14 \cdot 0$ & $15 \cdot 0$ & - & $14 \cdot 8$ & $0 \cdot 7$ \\
\hline 6. F.Z. & - & - & $7 \cdot 7$ & $7 \cdot 9$ & $11 \cdot 1$ & $9 \cdot 1$ & $12 \cdot 5$ & $10 \cdot 4$ & $9 \cdot 8$ & $1 \cdot 9$ \\
\hline 7. M.B. & - & - & $15 \cdot 3$ & - & - & $12 \cdot 8$ & $13 \cdot 6$ & $15 \cdot 3$ & $14 \cdot 3$ & $1 \cdot 3$ \\
\hline 8. T.L. & $12 \cdot 6$ & - & $15 \cdot 1$ & $14 \cdot 0$ & $14 \cdot 9$ & $10 \cdot 8$ & $17 \cdot 1$ & $15 \cdot 2$ & $14 \cdot 2$ & $2 \cdot 0$ \\
\hline 9. T.H. & $12 \cdot 4$ & - & $22 \cdot 5$ & $15 \cdot 4$ & $20 \cdot 5$ & $18 \cdot 8$ & - & $15 \cdot 1$ & $18 \cdot 5$ & $2 \cdot 6$ \\
\hline 10. A.B. & - & $13 \cdot 4$ & $12 \cdot 6$ & - & $15 \cdot 0$ & $14 \cdot 3$ & - & $16 \cdot 6$ & $14 \cdot 4$ & $1 \cdot 6$ \\
\hline 11. D.A. & - & $9 \cdot 4$ & - & $10 \cdot 6$ & $10 \cdot 1$ & $13 \cdot 0$ & $15 \cdot 6$ & - & $11 \cdot 7$ & $2 \cdot 5$ \\
\hline 12. R.G. & - & $13 \cdot 9$ & $15 \cdot 0$ & $15 \cdot 9$ & $13 \cdot 6$ & $12 \cdot 0$ & $12 \cdot 9$ & $16 \cdot 1$ & $14 \cdot 2$ & $1 \cdot 6$ \\
\hline
\end{tabular}




\section{RESULTS}

Values for the cardiac output determinations during the 20-minute walks are presented in Table II. As seen in Fig. 2, considerable variation in cardiac output calculated according to Hamilton was evident during the prolonged exercise. Not only did cardiac output vary within

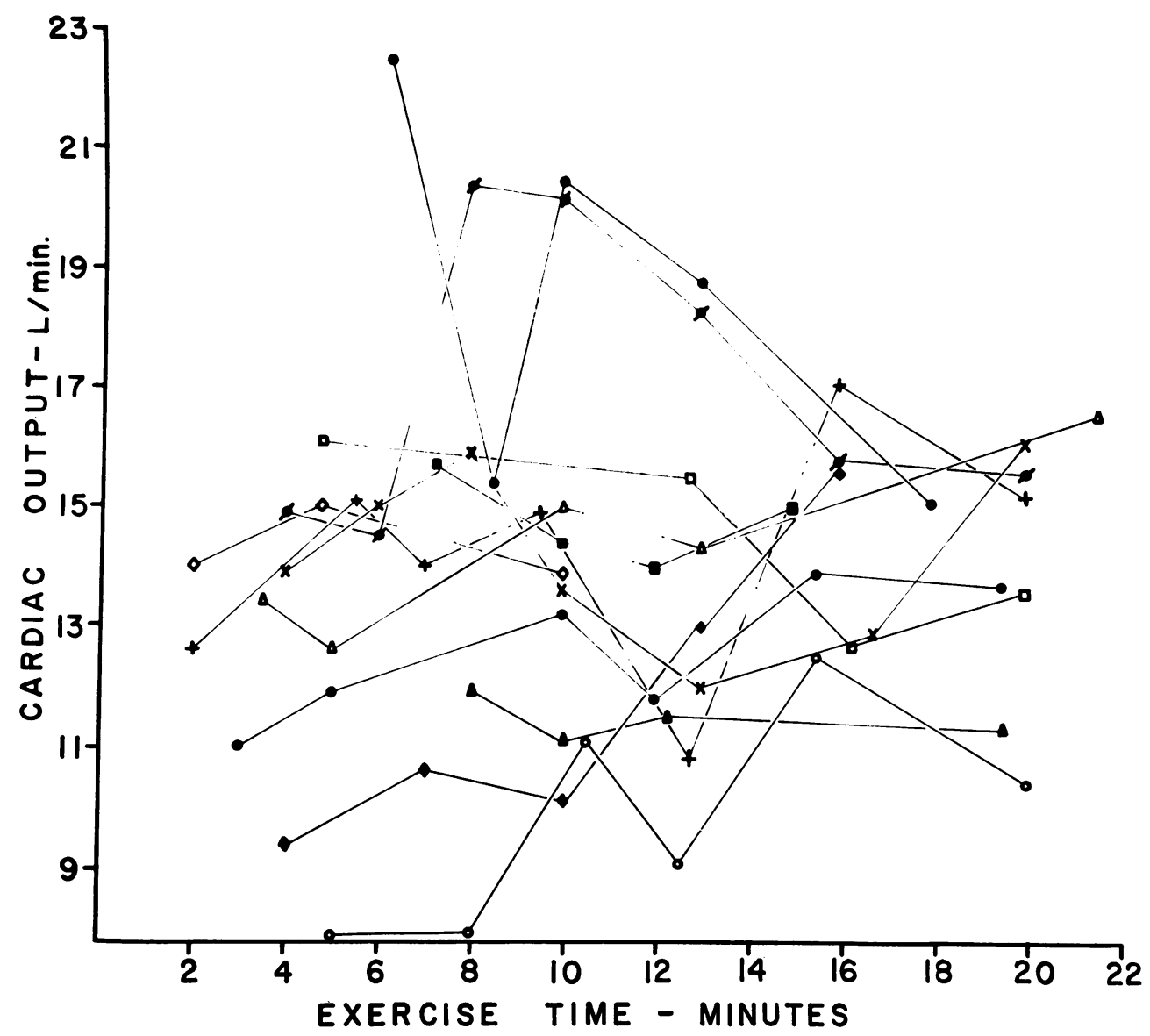

FIG. 2.-Variations in cardiac output in 12 subjects over 20-minute periods of treadmill exercise.

the group between extremes of $7 \cdot 7-22 \cdot 51 . / \mathrm{min}$., but fluctuations as great as $7 \cdot 01 . / \mathrm{min}$. were observed in some individuals. Of the total 12 subjects, 7 (Cases 1, 2, 3, 5, 7, 10 and 12) maintained reasonably steady output levels, the greatest variation between any two determinations being $4.01 . / \mathrm{min}$., and from the mean $2 \cdot 21 . / \mathrm{min}$. The remaining 5 subjects all demonstrated a circulatory steady state during portions of this prolonged walk, but could not maintain a constant cardiac output throughout. This is typified by Case 8 whose output level was very steady during the first 10 minutes of the walk, but subsequently both decreased and increased greatly. These results contrast with those of the ventilatory studies (Table III) in which all 12 subjects maintained a steady state as evidenced by variations from the mean of $0.5-9.5$ per cent for minute volume, 1.0-5.0 per cent for oxygen uptake, and $2 \cdot 0-4 \cdot 5$ per cent for carbon dioxide elimination during their later walks.

From the total of 87 outputs, the pairs that were performed within two minutes of each other have been compared (Fig. 3). Such paired values showed only a 3.8 per cent average deviation from their mean, and as shown by the $r$ value of $0 \cdot 89$, a high degree of correlation was found. In 
addition, comparison of cardiac outputs in the same subject obtained at the 10th minute of two successive walks was made, and gave a value of $r=0 \cdot 64$ (Fig. 4).

\section{DisCUSSION}

Reliability of indicator dilution curves in determining cardiac output and the close correlation of this method with the Fick principle has been discussed by many investigators (Hamilton et al., 1948; Werkö et al., 1949; Doyle et al., 1953; Neeley et al., 1954; Richardson et al., 1959; Kopelman

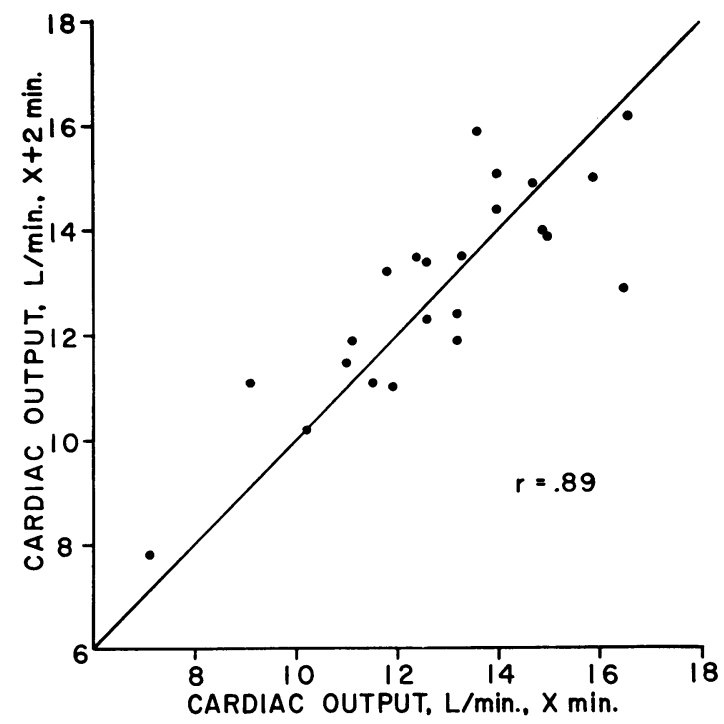

FIG. 3.-Correlation between all cardiac outputs performed within two minutes of each other in the same subject.

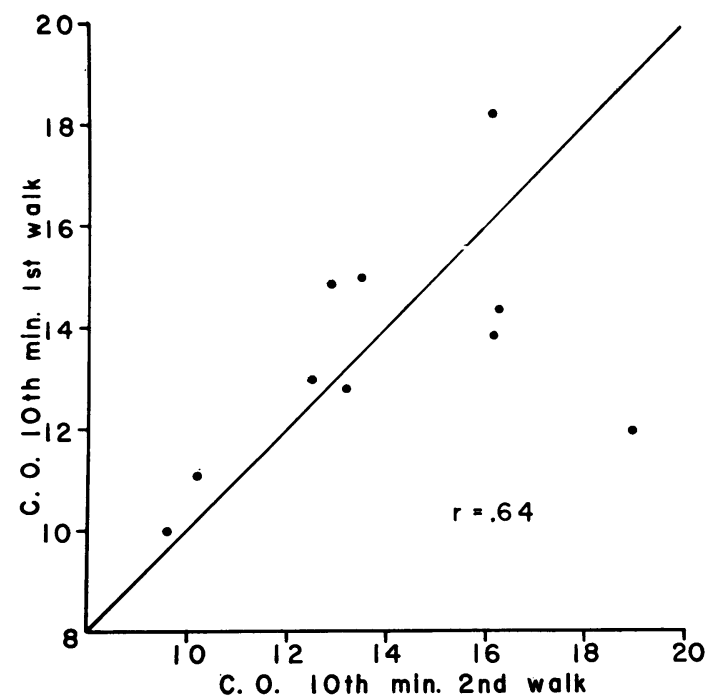

FIG. 4.-Correlation of cardiac outputs in same subject determined at the 10 th minute of two separate 20 -minute walks. 
and Lee, 1951). In the present investigation, reproducibility of results in paired determinations was considered more important than correlation with the Fick principle. To establish reproducibility in our hands, duplicate resting cardiac output determinations were made in 15 consecutive cardiac patients seen in this faculty. The $r$ value of these pairs was 0.999 , and the average deviation $170 \mathrm{ml}$. The high degree of correlation $(r=0 \cdot 89)$ between such pairs taken during exercise has already been mentioned. Further assurance of reliability is provided by the fact that all outputs in this report were calculated from sharp curves (Fig. 1), each of which when plotted on semi-log paper gave a straight-line descending slope of the curve.

Use of the "forward triangle" method for calculation of cardiac output has been suggested (Hetzel et al., 1958), at least for those curves in which recirculation occurs early or is not separated easily from the primary curve. In our study, such difficulty with curve analysis was not encountered, and results of the Hetzel method are presented (Fig. 5) as an interesting comparison with those of the more widely employed Hamilton calculation. The fairly good correlation of the two methods agrees with earlier reports.

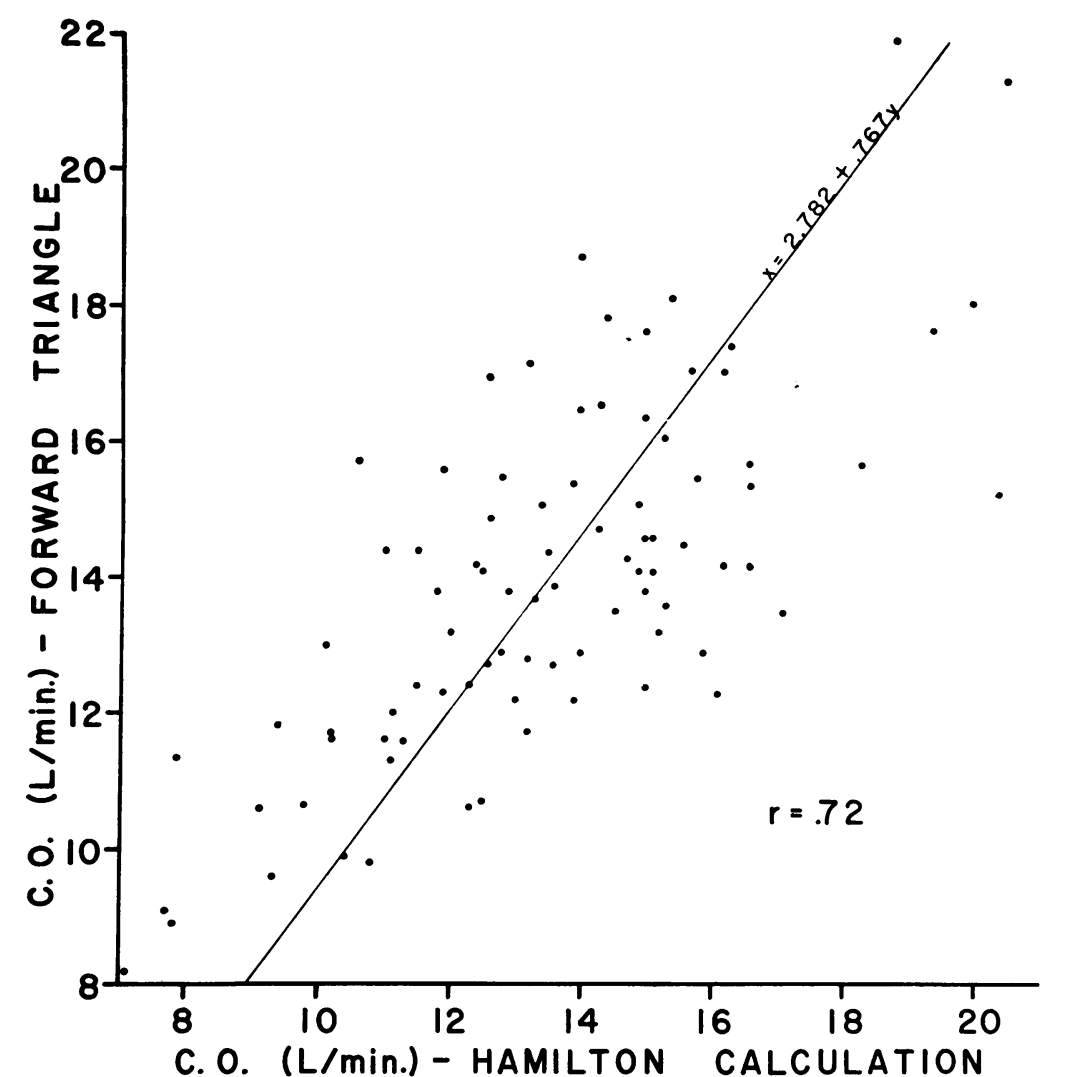

FIG. 5.-Correlation of values obtained for cardiac output when calculated by both method of Hamilton and "forward triangle". Regression line for these values is plotted.

Previous studies of cardiac output during exercise in normal subjects have in the main been restricted to recumbency (Kowalski et al., 1954; Freedman et al., 1955-56; Dexter et al., 1950-51; Hickam and Cargill, 1948; Donald et al., 1955; Barrott-Boyes and Wood, 1957). Attention has been focused primarily on differences between cardiac output at rest and after short periods of exercise. Donald et al. (1955) have studied cardiac output in recumbent, exercising subjects and 
noted the minute-by-minute variations over a five-minute period. However, to our knowledge, there are no reports that extend such "steady-state" observations in normal subjects beyond five minutes. In Donald's study, exercise levels comparable with those of the present report in terms of oxygen uptake (Table III) were reached in eight subjects. Seven of these appeared to maintain a steady cardiac output during the last four minutes of the five-minute walk.

TABLE III

VeNTILATORY STUDiEs

\begin{tabular}{|c|c|c|c|c|c|c|c|c|c|c|c|c|}
\hline \multirow{3}{*}{$\begin{array}{l}\text { Subject \# } \\
\text { 1. J.G. . . }\end{array}$} & \multicolumn{4}{|c|}{$\begin{array}{l}\text { Minute volume } \\
\text { 1./min. S.T.P.D. }\end{array}$} & \multicolumn{4}{|c|}{$\begin{array}{c}\mathrm{O}_{2} \text { uptake } \\
\mathrm{ml} . / \mathrm{min} .\end{array}$} & \multicolumn{4}{|c|}{$\begin{array}{l}\mathrm{CO}_{2} \text { elimination } \\
\mathrm{ml} / \mathrm{min} .\end{array}$} \\
\hline & 1 & 2 & 3 & 4 & 1 & 2 & 3 & 4 & 1 & 2 & 3 & 4 \\
\hline & $25 \cdot 3$ & $27 \cdot 9$ & $30 \cdot 7$ & $29 \cdot 1$ & 1536 & 1601 & 1630 & 1545 & 1159 & 1244 & 1292 & 1138 \\
\hline 2. D.B. & $24 \cdot 4$ & $23 \cdot 1$ & $22 \cdot 1$ & $23 \cdot 3$ & 1420 & 1414 & 1397 & 1354 & 1186 & 1146 & 1129 & 1132 \\
\hline 3. P.R. . . & $24 \cdot 0$ & $25 \cdot 0$ & $24 \cdot 2$ & $25 \cdot 3$ & 1366 & 1320 & 1392 & 1384 & 1152 & 1200 & 1162 & 1187 \\
\hline 4. G.Y. .. & $23 \cdot 1$ & $24 \cdot 6$ & $24 \cdot 9$ & $26 \cdot 7$ & 1508 & 1547 & 1566 & 1586 & 1180 & 1220 & 1285 & 1266 \\
\hline 5. P.W. & $22 \cdot 3$ & $24 \cdot 1$ & $25 \cdot 9$ & $26 \cdot 7$ & 1296 & 1347 & 1399 & 1386 & 1050 & 1099 & 1103 & 1204 \\
\hline 6. F.Z. & $28 \cdot 6$ & $27 \cdot 7$ & $28 \cdot 3$ & $28 \cdot 4$ & 1361 & 1382 & 1398 & 1401 & 1104 & 1014 & 1007 & 1011 \\
\hline 7. M.B. .. & $26 \cdot 3$ & $29 \cdot 7$ & $29 \cdot 7$ & $29 \cdot 4$ & 1512 & 1631 & 1636 & 1664 & 1278 & 1295 & 1295 & 1282 \\
\hline 8. T.L. $\quad$. & $33 \cdot 7$ & $30 \cdot 9$ & $33 \cdot 9$ & $32 \cdot 9$ & 1570 & 1542 & 1566 & 1546 & 1267 & 1162 & 1241 & 1171 \\
\hline 9. Т.Н. .. & $22 \cdot 2$ & $24 \cdot 0$ & $25 \cdot 0$ & $22 \cdot 8$ & 1447 & 1442 & 1463 & 1386 & 1212 & 1286 & 1303 & 1190 \\
\hline 10. A.B. $\quad$. & $22 \cdot 3$ & $24 \cdot 9$ & $25 \cdot 9$ & $24 \cdot 9$ & 1327 & 1379 & 1417 & 1367 & 1050 & 1086 & 1129 & 1073 \\
\hline 11. D.A. . & $29 \cdot 8$ & $30 \cdot 0$ & $30 \cdot 0$ & $30 \cdot 1$ & 1576 & 1650 & 1662 & 1628 & 1183 & 1278 & 1248 & 1174 \\
\hline 12. R.G. .. & $26 \cdot 2$ & $27 \cdot 9$ & $28 \cdot 0$ & $25 \cdot 2$ & 1488 & 1518 & 1523 & 1464 & 1182 & 1189 & 1207 & 1149 \\
\hline
\end{tabular}

$1=5$ th and 6 th minutes of exercise

$2=11$ th and 12 th minutes

$3=15$ th and 16 th minutes

$4=20$ th minute

Had the cardiac outputs in this study been determined only over a period of 5 to 10 minutes 11 of the 12 subjects would be reported as maintaining a steady cardiac output. Furthermore, the high correlation shown in Fig. 3 between outputs done within 2 minutes of each other supports the conclusion that a steady state exists over short periods of exercise. However, in prolonging exercise for an additional 10 to 15 minutes, 4 of these 11 "steady" subjects showed wide variations in output.

In the present study it was technically impossible to obtain simultaneous measurements of oxygen uptake and cardiac output. Although our subjects showed a ventilatory steady state in subsequent walks, we cannot exclude entirely the possibility of some variation in oxygen uptake during the actual output determinations. However, previous studies in this laboratory (Tabakin and Hanson, 1960) have indicated that any normal subject will exhibit a steady ventilatory state in terms of oxygen uptake for any given 20-minute walk. If oxygen uptake was indeed steady during the output walks, we must assume that A-V oxygen changes occurred in the five subjects whose outputs varied. We are unable to relate the specific roles of fatigue, regional blood flow change, and variations in tissue oxygen extraction to our observations. Caution is urged in the interpretation and application of data in procedures demanding a circulatory steady state over long periods of time. 


\section{SUMMARY}

Eighty-seven cardiac output determinations have been carried out in 12 normal men using indicator-dilution techniques. All determinations were made during "steady-state" treadmill exercise. Reliability of the method under these conditions has been demonstrated. Although cardiac outputs were almost invariably steady for each subject for short time intervals, significant variations were observed in five subjects when exercise was prolonged to 20 minutes. These observations assume importance in many investigations requiring attainment and maintenance of uniform cardiac output.

The authors gratefully acknowledge the technical assistance of Drs. A. Caldwell, E. Caldwell, and L. Gettes; and also of Mrs. Reba J. Beecher, R.N., Mrs. Leona Amelia, R.N., and Mrs. Nellie Cairns.

\section{REFERENCES}

Barrott-Boyes, B. G., and Wood, E. H. (1957). J. appl. Physiol., 11, 129.

Chapman, C. B., and Fraser, R. S. (1954). Circulation, 9, 57.

Dexter, L., Whittenberger, J. L., Haynes, F. W., Goodale, W. T., Gorlin, R., and Sawyer, C. G. (1950-51). J. appl. Physiol., 3, 439.

Donald, K. W., Bishop, J. M., Cumming, G., and Wade, O. L. (1955). Clin. Sci., 14, 37.

Doyle, J. T., Wilson, J. S., Lepine, C., and Warren, J. V. (1953). J. Lab. clin. Med., 41, 29.

Freedman, M. E., Snider, G. L., Brostoff, P., Kimelblot, S., and Katz, L. N. (1955-56). J. appl. Physiol., 8, 37.

Hamilton, W. F., Moore, J. W., Kinsman, J. M., and Spurling, R. G. (1932). Amer. J. Physiol., 99-100, 534.

Hamilton, W. S., Riley, R. L., Attyah, A. M., Cournand, A., Fowell, D. M., Himmelstein, A., Noble, R. P., Remington, J. W., Richards, D. W., Jr., Wheeler, N. C., and Witham, A. C. (1948). Amer. J. Physiol., 153, 309.

Hetzel, P. S., Swan, H. J. C., Ramirez DeArellano, A. A., and Wood, E. H. (1958). J. appl. Physiol., 13, 92.

Hickam, J. B., and Cargill, W. H. (1948). J. clin. Invest., 27, 10.

Kopelman, H., and Lee, G. de J. (1951). Clin. Sci., 10, 383.

Kowalski, H. J., Abelmann, W. H., McNeely, W. F., Frank, N. R., and Ellis L. B. (1954). Amer. J. med. Sci., 228, 622 .

Levy, A. M., Hanson, J. S., and Tabakin, B. S. (1961). J. appl. Physiol., 16, 309.

Mitchell, J. H., Sproule, B. J., and Chapman, C. B. (1958). J. clin. Invest., 37, 538.

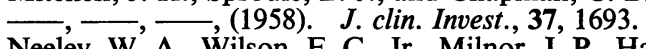

Neeley, W. A., Wilson, F. C., Jr., Milnor, J. P., Hardy, J. D., and Wilson, H. (1954). Surgery, $35,22$.

Richardson, D. W., Jr., Wyso, E. M., Hecht, A. M., and Fitzpatrick, D. P. (1959). Circulation, $20,1111$.

Sproule, B. J., Mitchell, J. H., and Miller, W. F. (1960). J. clin. Invest., 39, 378.

Tabakin, B. S., and Hanson, J. S. (1960). J. appl. Physiol., 15, 579.

Werkö, L., Lagerlöf, H., Bucht, H., Wehle, B., and Holmgren, A. (1949). J. Lab. clin. Med., 1, 109. 